REVIEW

\title{
How, and when, can I restrain a patient?
}

\section{Horsburgh}

Postgrad Med J 2004;80:7-12. doi: 10.1136/pgmi.2003.007302

The need to restrain service users will vary according to the area of practice within which practitioners are employed. Many of the principles that relate to the issue of restraining service users are, however, applicable to all, or most, health and social care settings. While the emphasis should be on pre-emptive action, wherever possible, in order to prevent the need to restrain, there are some occasions on which the risks to the service user, or others, of inaction may outweigh those of taking action. Some of the key issues are discussed in this paper.

Correspondence to:

Dr Dorothy Horsburgh,

School of Acute and Continuing Care Nursing, Faculty of Health and Life Sciences, Napier University, 74 Canaan Lane, Edinburgh EH9 2TB, UK; d.horsburgh@napier. ac.uk

Submitted

3 September 2003

Accepted 14 October 2003
$\mathrm{T}$ he use of restraint in health and social care is controversial, both in legal and moral terms. Restraint is defined in the New Shorter Oxford English Dictionary" as the "deprivation or restriction of liberty or freedom of action or movement". Restraint may involve the physical containment of one individual by another person or persons, with or without the use of mechanical aids. It may comprise the use of equipment (for example door locks) to ensure that an individual cannot move outwith a prescribed area. More subtle restraints may also be employed, for example removing walking aids from an individual's reach, or ensuring that the environmental temperature in certain areas within care settings discourages loitering. The application of electronic tagging devices can alert staff to the movement of an individual outwith a desired area and thus enables their apprehension. Chemical restraint of individuals may be achieved by the use of sedative medication, on either a short or long term basis.

While the foregoing measures breach individual autonomy-that is, the right to make one's own decisions-the justification in health and social care settings is usually that restraint is in the service user's best interest (the ethical principle of beneficence) and/or is carried out in order to prevent the individual coming to harm (the principle of non-maleficence). If a further rationale is provided, it may be that, while autonomy is a prima facie principle (that is, at first sight appears to be one that should be upheld), it is predicated upon an individual having insight into the consequences of their actions. This then is used to justify, for example, the restraint of a young child while they are given an injection, or of a vulnerable adult who attempts to leave a care setting. A further principle, however, that must be taken into the equation is that of justice, which may be applied in strictly legal terms, or may include the morality or otherwise of an action or inaction, aside from its legal repercussions.

The purpose of this review article is to examine the circumstances under which it may be justifiable to restrain a patient and the acceptable means by which such restraint may be achieved. It is, however, emphasised that, wherever possible, the use of restraint should be avoided and alternatives sought.

The law in the UK entitles individuals to freedom of movement, provided that they are not harming others in exercising that right. Being subject to restraint outwith this definition provides the individual being restrained with the option of taking legal action against the individual(s) perpetrating the restraint. The charge resulting from the use of restraint will depend on the reasons for the restraint, the severity of the means of restraint, and the potential or actual physical or psychological damage caused (that is, assault at one end of the continuum and murder, culpable homicide or manslaughter at the other).

The Law Society in the UK identifies specific safeguards that should be in place to govern the use of physical restraint. ${ }^{2}$ Restraint should not be used for the purpose of punishment, but only to control violent behaviour in order to protect either the service user or others. The "best" method of restraint must be identified on an individualised basis, taking into account the specific circumstances pertaining at the time. Use of restraint should be monitored by an independent body, for example the Mental Health Act Commission in England and Wales, the Mental Welfare Commission for Scotland, or the Mental Health Commission for Northern Ireland, to ensure compliance with legislation and good practice.

The Department of Health for England and Wales advises that inappropriate use of restrictive physical intervention may give rise to criminal charges, action under civil law, or prosecution under health and safety legislation. ${ }^{3}$ Justification for physical intervention may be the need to prevent accidental or deliberate harm to a service user or others. Situations in which such justification exists will be the subject of more detailed discussion later in this paper. The Human Rights Act does not require the plaintiff to prove that actual physical or psychological harm has resulted from an infringement of the Act. ${ }^{4}$ (This differs from the civil law relating to negligence, which requires, first, that a duty of care was owed by the defendant to the plaintiff, second, that the duty of care was not fulfilled, and, third, that the plaintiff suffered actual harm as a consequence.) Employers are identified by the Department of Health for England and Wales 
as having a duty of risk assessment to protect employees, in addition to their duty of care to service users. ${ }^{3}$

In the following sections, the role of the healthcare practitioner in relation to service users with specific needs will be addressed. In the first instance there are, however, a number of generically relevant points to be made.

Practitioners are accountable to their service users, to colleagues (and to themselves as individuals and as practitioners), to their employer, to the law of the country within which they practise, and to their professional regulatory body. Each of these lines of accountability entails slightly different obligations on the part of the practitioner, but all require a demonstration that the actions or inactions have been those of a reasonable and competent practitioner. Failure to prove this may attract penalties dependent upon both the seriousness of the action/inaction and its consequences.

\section{GENERIC ISSUES}

The Human Rights Act, ${ }^{4}$ Article 3, states that "... no one shall be subjected to inhuman or degrading treatment or punishment". Article 5 states that "... everyone has the right to liberty and security of person", and Article 9 states that individuals should have "... freedom of thought, conscience and religion" (which may translate into refusal of certain treatment(s)). While the Human Rights Act $^{4}$ became effective in England, Wales, and Northern Ireland from 2000 (1999 in Scotland), its full implications will emerge only as and when specific cases are brought to court and interpretations of the law are translated into rulings.

Paterson et al have identified the lack of research in relation to some aspects of physical restraint, ${ }^{56}$ and, additionally, Peretz and Gluck, in relation to the use of restraint in paediatric dentistry, point to a wealth of literature about the success, in the short term, of using restraint, but virtually none that explores the long term psychological impact upon service users who have experienced it. ${ }^{7}$ There is no statutory requirement for health and social care providers in the UK to report situations in which restraint has been used, and there is no central recording of injuries or deaths resulting from restraint. Paterson et al therefore conducted a study to explore this knowledge gap. ${ }^{56}$ Their findings were that restraint involving neck holds had an unquestionably high risk of fatality, as did that which entailed obstruction of the nose or mouth. Mechanical restraints, such as garments, from which individuals had made unsuccessful escape attempts were also associated with a high risk of death, as were prone tying and hobble tying of patients. The term "prone tying" was not used in a homogeneously uniform way, but applied to a variety of ways in which patients were physically restrained while lying face down. Hobble tying is the term used to describe the prone positioning of a patient, following which their wrists are secured behind their back, their ankles are tied, and their wrists and ankles are subsequently secured together by pulling the shoulders back and bending the legs towards them. Seated restraint procedures are not, however, without risk, particularly if a position requiring hyperflexion is required, owing to possible respiratory compromise. Preexisting physical conditions, such as obesity, heart disease, general physical ill health, or exhaustion, provide additional risks. A summary of the factors associated with fatality during restraint is provided in box 1 .

Paterson et al concluded that restraint is intrinsically unsafe but that in some circumstances it may be less hazardous than the available alternatives. ${ }^{5} 6$ They identify the need to assess the risks associated with the use of restraint and the need for safeguards in order to prevent its misuse, including mandatory recording and reporting of all instances in which restraint has been employed. They also
Box 1: Factors associated with fatality during restraint

- Neck holds.

- Obstruction of nose and/or mouth.

- Mechanical restraints, for example garments or straps.

- Prone tying.

- Hobble tying.

- Hyperflexion.

- Obesity.

- Heart disease.

- General ill health.

- Exhaustion

- Sedation without supervision.

Paterson et $a^{56}$

emphasise the need for staff to be trained in the management of aggressive or violent behaviour from clients, including that which requires the use of restraint.

The Department of Health for England and Wales issued guidance in relation to the use of restrictive physical interventions by health and social care workers and stated that restrictive physical interventions that employ force should be used only in the circumstances described in box $2 .^{3}$

While specific organisations have developed guidelines for the use of restraint in their specific areas of practice (for example, psychiatry, learning disability), much of the advice that they provide is applicable to any health and social care setting, and, for this reason, the generically applicable information will be provided in the first instance.

Box 2: Restrictive physical interventions that employ force should be used only:

- When other strategies have failed; even when restraint is required, it should comprise one component of an overall care plan for the service user.

- In an emergency situation when the risk of inaction outweighs the risks of restraint

- With the minimum amount of force.

- For the shortest duration of time.

- In the best interest of the service user and/or to prevent harm to third parties.

- By staff who have received specialist training and employ only the techniques for which they have received a preparation for practice (employer responsibility).

- In a way that minimises the risk of physical injury and loss of dignity.

- Ensuring avoidance of contact that could be construed as sexual.

- With subsequent debriefing for staff and, where possible, the service user.

- With formal recording and reporting of the incident.

Department of Health for England and Wales ${ }^{3}$ 


\section{GUIDANCE FOR THE USE OF RESTRAINT}

The Royal College of Psychiatrists ${ }^{8}$ identified a dearth of quality research evidence relating to the use of restraint and subsequently issued guidelines ${ }^{8} 9$ relating to the management of imminent violence. While these were aimed at mental health service workers, much of their advice is relevant to any health and social care setting. It is, of course, of interest that the subject of restraint has been relatively unexplored. It may be that, rather than being considered unimportant, it is a subject that management and/or practitioners have been loathe to acknowledge and address. The Royal College of Psychiatrists emphasise the responsibility of management in providing quality care and their role in the development, dissemination, implementation, and monitoring of guidelines that relate to the restraint of service users. $^{89}$ They also emphasise the responsibility of staff to ensure that they have read and understood management's policies and procedures and to raise concerns, for example in relation to resource implications, if appropriate. ${ }^{89}$

The Royal College of Psychiatrists' guidelines ${ }^{89}$ emphasise $^{\prime}$ pre-emptive action, as does the British Institute of Learning Disability, ${ }^{10}$ in order to avoid the need, wherever possible, for physical restraint of service users. Settings in which care is provided should be secure and comfortable, with maintenance of an ambient temperature and access to daylight and fresh air. Privacy should be available for service users wherever possible, and their dignity should be preserved. Residential settings should be homely, and activities should be made available for service users. Noise and overcrowding should be minimised. Clients' concerns and frustrations should be acknowledged, discussed, and addressed, as these may otherwise escalate and create a situation in which restraint may be required.

In areas in which the potential for violence is recognised, staff should have unimpeded sight lines in relation to service users and accessible alarms. In such areas there must be a predetermined procedure for staff to follow in the event of an episode in which restraint of a service user is required.

All the foregoing points, including policies and procedures, should be developed in conjunction, wherever possible, with service users, whose concerns should be actively addressed by staff. Members of the multidisciplinary team must communicate and cooperate in the implementation of policies and procedures, and management must ensure adequate preparation for, and updating of, practice in restraint techniques for those staff who may be required to carry out physical restraint of service users.

The responsibility of staff is to assess the risk of, and anticipate, situations arising in which physical restraint of service users may be required. If a service user becomes verbally and/or physically antagonistic, the measures outlined in box 3 should be taken.

If the use of restraint is required then the method should be appropriate to the age, size, physical condition, and sex of the service user. The minimum amount of force should be applied, for the shortest possible duration. Adequate numbers of staff should be rapidly moved to the scene of the incident, if they are not already present. (The presence of adequate numbers of staff may in itself avoid situations in which restraint may be required.) The presence of adequate numbers of experienced staff in a situation in which restraint is necessary is likely to reduce the amount of force required and the likelihood of injury to service users or staff. Other service users, members of the public, and staff whose assistance is not required should remove themselves, or be removed with assistance, from the scene.

No restrictive measures involving neck compression should be used, and the service user's airway and head should be protected from obstruction and/or injury. An explanation of
Box 3: In response to verbal and/or physical aggression from service users, staff should

- Engage in conversation with the service user and acknowledge their concerns.

- Appear calm, self controlled, and confident.

- Maintain an adequate distance from the service user.

- Move towards a place of safety, for example where there is access to a doorway.

- Ensure that their own non-verbal communication is non-threatening.

- Ask the service user for facts and encourage reasoning.

- Ask for any weapon to be put down (not handed over).

- Explain their intentions to the service user (and others who may be present).

- Consider what means of physical restraint would be most appropriate in the situation, should it be required.

Royal College of Psychiatrists ${ }^{8}$

events should be provided by staff to the service user throughout the procedure, as calmly and clearly as possible. The possibility of chemical restraint using medication that has a rapid action and elimination should be considered. Mental health service users who participated in the Royal College of Psychiatrists' research unit's discussion group ${ }^{8} 9$ reported that medication was considered preferable to prolonged restraint.

The aim of rapid tranquillisation in the restraint of adult service users is to achieve sedation that will minimise the risk to the service user and/or others. ' Some antipsychotic drugs, for example droperidol, have a rapid effect and elimination, as do some benzodiazepines, for example lorazepam, administered either orally or by intramuscular or slow intravenous injection. ${ }^{9}$ Such medication should be prescribed only by an experienced physician, as assessments of the service user's state of physical and psychological arousal, the possibility of their having misused drugs, and their pre-existing physical condition are all required, in order to minimise the risks associated with sedation. The potential side effects of sedative medication, such as loss of consciousness as opposed to sedation, respiratory depression or arrest, cardiovascular complications, and seizures, must be monitored by experienced staff. No service user whose conscious level has been compromised by medication should be left unattended, even for a short time. ${ }^{9}$ Medication that may be used in the sedation of children will be identified and discussed later in this paper.

The British Institute for Learning Disability ${ }^{10}$ have guidelines similar to those of the Royal College of Psychiatrists, ${ }^{8} 9$ and they additionally emphasise that training of staff should be carried out by instructors who have appropriate experience and qualifications. Staff should implement only those restrictive interventions that they have been taught to use and should receive regular updates of their practice.

Following any use of physical intervention it is vital not only to report and record the incident in detail but also to reflect upon it by means of a staff (and, where possible, service user) debrief. This should enable the identification of precipitating factors and facilitate their minimisation in the future.

Having discussed the pre-emptive action that may be taken in order to minimise the occurrence of situations in which restraint may be required, it is important to discuss issues specific to certain groups of service users. 


\section{SERVICE USERS WHO HAVE A MENTAL HEALTH PROBLEM}

Sailas and Fenton, in a Cochrane Review, ${ }^{11}$ found that no controlled studies existed that evaluated the value of seclusion or restraint in those with serious mental illness, but that serious adverse effects following the use of restraint have been reported in qualitative studies. As noted earlier in this paper, it is a matter of interest and concern that the issue of restraint has not been explored in health care. Sailas and Fenton suggest that alternatives to restraint need to be developed, and they also identify the need for randomised trials in order to provide a credible evidence base for practice. ${ }^{11}$ Wright provided a critical review of the use of control and restraint techniques in the management of violence, while acknowledging the difficulty of achieving the degree of methodological rigour that usually underpins clinical trials. ${ }^{12}$

Bonner et al found that there is little published research on either the efficacy or the subjective effects of restraint on either the staff responsible for its implementation or the service users upon whom it was used. ${ }^{13}$ This dearth of evidence further highlights the lack of official acknowledgement of the use of restraint and the impact that it may have on those involved. Bonner et al carried out a pilot study, which found that incidents in which restraint of service users was required generated strong emotions for all concerned and that subsequent debriefing for staff was eclectic and for service users was rare. ${ }^{13}$ Marangos-Frost and Wells carried out a small scale qualitative study of mental health nurses who had been involved in the restraint of service users and found that they experienced these situations as a dilemma. ${ }^{14}$ They associated the use of restraint with a failure to protect and considered the negative effect on other service users as well as on the person who had been restrained. These nurses viewed restraint as a last resort and experienced a sense of dread when they anticipated its use. There would thus appear to be a need to investigate the impact of restraint upon both service users and staff and to identify ways in which staff may be better supported in their practice.

The Mental Welfare Commission for Scotland issued a good practice guidance for practitioners. ${ }^{15}$ This states that Section 24/25 of the Mental Health (Scotland) Act 1984 permits the use of restraint sufficient to ensure a service user's detention in hospital or upon their return if they have left without permission.

In developing new mental health legislation in Scotland the Millan Committee stated that service users should receive care, treatment, and support in the least restrictive manner and environment compatible with the delivery of safe and effective care, taking into account, where appropriate, the safety of others. ${ }^{16}$ This principle has now been enshrined in the Mental Health (Care and Treatment) (Scotland) Act $2003,{ }^{17}$ implementation of which is anticipated in 2004-5.

\section{ADULTS WHO ARE SERVICE USERS IN AN ACUTE PHYSICAL HEALTH SETTING}

The Mental Welfare Commission for Scotland states, in its good practice guideline, that restraint of an informal patient (that is, one who is not being held under a section of the Mental Health Act) may be justified by the common law duty of care..$^{15}$ Voluntary patients do not have the same rights as detained patients to information or recourse to the safeguards provided by the act, ${ }^{16}$ and many informal patients are unaware of their rights, including the rights of self discharge from a care setting and of treatment refusal. In situations in which a service user seeks self discharge against medical advice, their current mental state is of greater significance than their past medical history. In common law, irrationality is not, in itself, indicative of incapacity ${ }^{15}$ and may not justify the use of restraint.

\section{ADULTS WHO HAVE COGNITIVE IMPAIRMENT}

The majority of adults who have dementia are not detained under a section of the Mental Health (Scotland) $\mathrm{Act}^{18}{ }^{18}$ the Mental Health Act, ${ }^{19}$ or the Mental Health (Northern Ireland) Order $1986,{ }^{20}$ and therefore restriction on their liberty is not upheld in law. A conundrum does, however, exist. An individual who is receiving care from a medical practitioner or registered nurse is owed a duty of care in civil law by that person. If it is anticipated that a patient is unsafe in certain situations then the duty of care requires that the practitioner take measures to ensure the patient's safety or at least to minimise the risk of harm. If the practitioner fails to do this and the patient sustains significant harm as a result (for example by falling down stairs or by being injured while crossing the road) then the practitioner may be charged with negligence. They may also, of course, be subject to disciplinary proceedings by their employer and/or investigation by their professional regulatory body if the action or inaction is deemed to constitute misconduct. This recalls the point made earlier that practitioners have a number of lines of accountability in relation to their practice.

Intervention without consent constitutes battery in law unless the patient is incapable of giving consent. In Scotland, the Adults With Incapacity Act $^{21}$ permits treatment to be provided to individuals who are incapable of giving, or withholding, consent.

While there appears to be no clear cut advice regarding the justification for restraining an individual who has cognitive impairment and who constitutes a danger to themselves (or, rarely, to others), the principles of non-maleficence and beneficence have been used to support the use of restraint, at least in the short term, for individuals who are in health and social care settings. It should be emphasised, however, that if the use of restraint is necessitated by inadequate staffing levels then this issue needs to be addressed as a matter of urgency by management. It is the individual practitioner's responsibility to ensure that concerns about resources are brought to the attention of management, preferably in writing. All instances in which restraint is used should be reported and recorded.

(Price et al, in a Cochrane Review, ${ }^{22}$ assessed the effect of subjective barriers (for example, mirrors, camouflage, grids, or stripes of tape) in preventing individuals with cognitive impairment from wandering. They found no randomised controlled or controlled trials in relation to their use and therefore concluded that there is no evidence that subjective barriers are successful.)

\section{ADULT PATIENTS WHO HAVE A LEARNING DISABILITY}

The British Institute for Learning Disability emphasises the need for what it terms "physical interventions" to be carried out within a legal and ethical framework setting out explicit safeguards for the service user and staff. ${ }^{10}$ Their definition of a physical intervention is a method of responding to challenging behaviour that involves a degree of direct physical force and that limits or restricts the movement or mobility of the service user. (It is thus sufficiently similar to the term "restraint" for the two terms to be used synonymously in this paper.) Central to the use of restraint for service users who have a learning disability is the need for staff training in restraint strategies and techniques by qualified trainers to a set of quality standards. The Department of Health provides detailed guidance on the use of physical interventions for individuals who have a 
learning disability or autistic spectrum disorder in health and social care settings. ${ }^{3}$

\section{CHILDREN WHO ARE PATIENTS}

The United Nations' Convention on the Rights of Children was based on the premise that children are active and contributing participants in society. ${ }^{23}$ Article 12 states that children's views must be considered and taken into account in all matters concerning them and should be accorded weight dependent on the age and maturity of the individual child. The Council of Europe, in relation to children, stated that they should have the right to receive information in keeping with their age and their mental, emotional, and psychological development. ${ }^{24}$ Children should be treated with tact, discretion, and understanding and have their privacy respected. The Children Act 1989 (England and Wales) ${ }^{25}$ established the right of children to be involved in decisions about their welfare. The Children (Northern Ireland) Order $1995^{26}$ is closely modelled on the above, and the Children (Scotland) Act $1995^{27}$ explicitly states that the child's interests should be paramount and that their views must be taken into account in decision making.

Collins stated that, until recently, restraint of children was uncontested and accorded minimal discussion and that restraint remains accepted practice during immunisation by injection, venepuncture, and lumbar puncture. ${ }^{28}$

Gray suggests that the cumulative effect of the United Nations convention and UK legislation in conjunction with societal changes in the perception of children has resulted in restraint being perceived unfavourably and as constituting outdated practice. ${ }^{29}$

Pederson and Harbaugh stated that lack of knowledge and lack of time to employ distraction techniques were reasons cited for the use of restraint, ${ }^{30}$ and the survey of paediatric nurses in England carried out by Robinson and Collier ${ }^{31}$ suggested that restraint was perceived as a rapid and easy method of ensuring that procedures were completed quickly and safely, although it was also identified by over $69 \%$ of respondents as a leading cause of distress to children. Collins proposed that the use of restraint is indicative of a lack of understanding of the value of distraction and relaxation techniques in reducing pain and distress in children undergoing procedures. ${ }^{28}$ Gay described the use, in an English accident and emergency department, of dolls to provide a visual demonstration of procedures to children. ${ }^{32}$ The opportunity, where possible, to handle real or modified equipment was also found to be useful as a strategy for reducing anxiety in children. Collins identified the need for nurses to be better educated in alternatives to restraint and in restraint techniques, but acknowledged, however, that it is problematic when a child appears to understand what is proposed, but refuses to cooperate. ${ }^{28}$ Collins acknowledged the conflict between violating the child's human rights by employing restraint and the desire to do what is perceived to be in the best interest of the child. ${ }^{28}$ Collins also found that the amount of training that nurses receive in this area of practice is variable and that there is a need for them to receive better education in restraint techniques, should such measures be required. ${ }^{28}$

Gray discusses the use of conscious sedation in children. ${ }^{29}$ He points out that ketamine has been used by emergency room clinicians in the USA for more than 20 years, but that its use remains controversial in the UK. The sedative drugs most commonly prescribed for children in accident and emergency departments in the UK are chloral hydrate, midazolam, and nitrous oxide. Oral and nasal routes of administration avoid the need for injection. Chloral hydrate, while relatively safe, is not always an effective sedative and, when successful, has a relatively prolonged sedation time.
Box 4: Key issues in relation to the use of restraint

- Assess the likelihood that the use of restraint will be required.

- Identify the feasibility of using alternatives.

- Assess the suitability of restraint for the individual service user-that is, potential or actual physical and psychological impact.

- Ensure that staff receive adequate education and training in restraint techniques.

- If restraint is required:

- Avoid the restraint techniques identified in box 1 .

- Use minimum force, for the shortest possible duration.

- Minimise the risk of harm to the service user(s) and staff.

- Ensure formal reporting and recording of the incident.

- Debrief staff and, where possible, the service user.

Reflect on the incident to enhance future practice.

Midazolam is anxiolytic, sedative, hypnotic, and amnesic, but has the potential to cause respiratory depression or arrest. Nitrous oxide provides rapid sedation of short duration, but requires continuous inhalation by a cooperative child who is able to retain a mask in position over their mouth and nose. ${ }^{29}$ Gray argues that ketamine is effective, both in terms of pain relief and in ensuring child compliance during treatment. Ketamine may be administered by oral, rectal, intramuscular, or intravenous routes and produces rapid sedation with analgesia and amnesia. Ketamine does, however, induce dissociation from the recipient's environment, and thus the individual may be unable to respond to physical and verbal commands; the drug therefore does not meet the criteria most commonly used for "conscious sedation". ${ }^{29}$ The use of ketamine (or any other sedative agent) is not without risks, and it should be prescribed, administered, and monitored only by experienced medical and nursing staff.

The Royal College of Nursing in the UK published guidelines in response to anxieties raised about the restraint of children in healthcare settings. ${ }^{33}$ The Royal College of Nursing distinguished between "holding", which they

\section{Key references}

- British Institute of Learning Disability. Factsheet no.10: physical interventions. www.bild.org.uk/factsheets/ physical_interventions.htm (accessed 13 August 2003).

- Department of Health. Guidance for restrictive physical interventions: how to provide safe services for people with learning disabilities and autistic spectrum disorder in health and social care settings. London: Department of Health, 2002. Also available from www.doh.gov. uk/learningdisabilities/physicalintervention.pdf (accessed 13 August 2003).

- Royal College of Nursing. Restraining, holding still and containing children, guidance for good practice. London: Royal College of Nursing, 1999.

- Royal College of Psychiatrists. The management of imminent violence: clinical practice guidelines to support mental health services. London: Royal College of Psychiatrists, 1998. 
defined as requiring a lesser degree of force and performed with a different intention from restraint, and "containing and preventing from leaving", which is the use of physical restraint or a barrier to prevent a child from leaving, harming themselves, or causing serious damage. Restraint had previously been defined by the Department of Health for England and Wales as "... the positive application of force with the intention of overpowering the child". ${ }^{34}$ The Royal College of Nursing' $\mathrm{s}^{33}$ principles of practice are in many ways similar to those outlined earlier in this paper. They emphasise that prior explanations of procedures to the child and the use of alternatives, such as distraction, should constitute the first line of intervention and that restraint, holding, and containing should be the last resort. Parental involvement, if desired by parent and child, is desirable. The need for management to develop policies and procedures detailing permissible methods of restraint, the situations in which restraint may be acceptable, and the reporting and recording of such incidents was identified. (Lambrenos and McArthur provide a detailed description of the introduction of a clinical holding policy. ${ }^{35}$ )

Open discussion about the child's best interest should be encouraged among staff, and there should be a clear mechanism by which staff may make any disquiet known. Allocation of adequate numbers of staff who have received education in alternatives to restraint and in methods of restraint is the responsibility of management. The minimum amount of restraint should be applied, for the shortest duration possible, with concomitant explanations to the child. Debriefing of the child, parents, and staff should take place as soon as possible after incidents in which restraint has been required.

\section{CONCLUSION}

The need to restrain service users will vary according to the area of practice within which the practitioner is employed. It may be seen, however, that many of the principles relating to the issue of restraining service users are applicable to all, or most, health and social care settings. While the emphasis should be on pre-emptive action, wherever possible, in order to prevent the need to use restraint, there are some occasions on which the risks to the service user or others of inaction may outweigh those of taking action. Some of the key issues discussed in this paper are summarised in box 4 .

\section{REFERENCES}

1 Brown L, ed. The new shorter Oxford English dictionary. Oxford: Clarendon Press, 1993.

2 The Law Society. Available at: www.lawsoc.org.uk (accessed 08 August 2003).

3 Department of Health. Guidance for restrictive physical interventions: how to provide safe services for people with learning disabilities and autistic spectrum disorder in health and social care settings. London: Department of Health, 2002. Also available from www.doh.gov.uk/learningdisabilities/ physicalintervention.pdf (accessed 13 August 2003).

4 Human Rights Act. London: HMSO, 1998.

5 Paterson B, Bradley P, Stark C, et al. Deaths associated with restraint use in health and social care in the UK. The results of a preliminary survey. J Psychiatr Ment Health Nurs 2003;10:3-15.

6 Paterson B, Bradley P, Stark C, et al. Restraint-related deaths in health and social care in the UK: learning the lessons. Ment Health Pract 2003;6:11-17.

7 Peretz B, Gluck GM. The use of restraint in the treatment of paediatric dental patients: old and new insights. Int J Paediatr Dent 2002;12:392-7.

8 Royal College of Psychiatrists. The management of imminent violence: clinical practice guidelines to support mental health services. London: Royal College of Psychiatrists, 1998

9 Royal College of Psychiatrists. Management of imminent violence: quick reference guide. www.rcpsych.ac.uk/publications/guidelines/ violence_quickref.htm (accessed 07 August 2003).

10 British Institute of Learning Disability. Factsheet no. 10: physical interventions. Available at: www.bild.org.uk/factsheets/physical_interventions.htm (accessed 13 August 2003).

11 Sailas E, Fenton M. Seclusion and restraint for people with serious mental illness. Cochrane Library. Issue 3. Oxford: Update Software, 2003.

12 Wright $\mathbf{S}$. Control and restraint techniques in the management of violence in inpatient psychiatry: a critical review. Med Sci Law 2003;43:31-8.

13 Bonner G, Lowe T, Rawcliffe D, Wellman N. Trauma for all: a pilot study of the subjective experience of physical restraint for mental health inpatients and staff in the UK. J Psychiatr Ment Health Nurs 2002;9:465-73.

14 Marangos-Frost S, Wells D. Psychiatric nurses' thoughts and feelings about restraint use: a decision dilemma. J Adv Nurs 2000;31:362-9.

15 Mental Welfare Commission for Scotland. Good practice guidance: general hospitals and the Mental Health (Scotland) Act 1984. Edinburgh: Scottish Executive Health Department, updated July 2002.

16 Scottish Executive. Review of literature relating to mental health legislation. Available at: www.scotland.gov.uk/ (accessed 21 November 2002).

17 Scottish Executive Health Department. Reforming mental health law, 2003. www.scotland.gov.uk/library5/health/mhnl1-00.asp (accessed 25 August 2003).

18 Mental Health (Scotland) Act. London: HMSO, 1984

19 Mental Health Act. London: HMSO, 1983.

20 Mental Health (Northern Ireland) Order. London: HMSO, 1986

21 Adults with Incapacity Act. Edinburgh: Scottish Executive, 2002.

22 Price JD, Hermans DG, Grimley Evans J. Subjective barriers to prevent wandering of cognitively impaired people. Cochrane Library. Issue 3. Oxford: Update Software, 2003.

23 United Nations. The United Nations Convention on the Rights of the Child. London: CRDU, 1989

24 Council of Europe. The need for a European Convention on children's rights. Strasbourg: Directorate of Human Rights, 1989.

25 Children Act. London: HMSO, 1989.

26 Children (Northern Ireland) Order. London: HMSO, 1995.

27 Children (Scotland) Act. London: HMSO, 1995.

28 Collins $\mathbf{P}$. Restraining children for painful procedures. Paediatr Nurs 1999:11:14-16.

29 Gray J. Conscious sedation of children in A\&E. Emerg Nurs 2002;9:26-31.

30 Pederson C, Harbaugh BL. Nurses' use of nonpharmacologic techniques with hospitalized children. Issues Compr Pediatr Nurs 1995;18:91-109.

31 Robinson S, Collier J. Holding children still for procedures. Paediatr Nurs 1997:9:12-14.

32 Gay J. Caring for children in A\&E. Paediatr Nurs 1991;3:21-3.

33 Royal College of Nursing. Restraining, holding still and containing children, guidance for good practice. London: Royal College of Nursing, 1999.

34 Department of Health. Guidance on permissible forms of control in children's residential care. London: HMSO, 1993.

35 Lambrenos K, McArthur E. Introducing a clinical holding policy. Paediatr Nurs $2003 ; 15: 30-3$ 